Katarina Zavišin*

Univerzitet u Beogradu

Filološki fakultet https://doi.org/10.18485/zivjez.2018.38.1.9

81'246.2(497.11)

Прегледни рад

\title{
DVOJEZIČNA (CLIL) NASTAVA U OBRAZOVNOM SISTEMU SRBIJE: SADAŠNJI IZAZOVI I PREDLOG SMERNICA ZA BUDUĆNOST
}

Predmet rada predstavlja opis trenutne organizacije dvojezične nastave u obrazovnom sistemu Republike Srbije sa izdvojenim izazovima pred kojima se nalaze učenici i nastavnici u datom kontekstu nastave. U radu je prikazan sadržaj Pravilnika o bližim uslovima za ostvarivanje dvojezične nastave sa posebnim osvrtom na nedostajuće elemente dokumenta kao što su: usavršavanje nastavnika, upotreba udžbenika, kriterijumi za ocenjivanje učenika i struktura završnog (maturskog) ispita na kraju srednjoškolskog ciklusa.

Na osnovu analize pomenutih aspekata u evropskoj praksi CLIL nastave, predložene su smernice za dalji razvoj dvojezične nastave u Republici Srbije sa posebnim osvrtom na elemente koji nedostaju u datom obrazovnom sistemu.

Ključne reči: dvojezična CLIL nastava, usavršavanje nastavnika, udžbenici, ocenjivanje, završni (maturski) ispit

\section{Uvod}

Pojam CLIL metode (engl. Content and Language Integrated Learning), poznat pod nazivom "Integrisano učenje jezika i sadržaja", odnosi se na dvojezičnu nastavu koja se odvija na stranom i maternjem jeziku. U CLIL nastavi učenici usvajaju nejezičke sadržaje (određeni nastavni predmet) posredstvom stranog jezika koji dobija takozvanu posrednu ulogu (engl. vehicular language) u ovom

katarina.zavisin@gmail.com 
obliku nastave. Na ovaj način strani jezik se usvaja istovremeno sa datim nejezičkim predmetom (Marš i dr. 2002).

Ovakav oblik nastave počeo je da se primenjuje u evropskim zemljama devedesetih godina XX veka čemu je prethodila rezolucija Evropske Komisije kojom se ističe značaj učenja stranih jezika, te se preporučuje uvođenje tri strana (evropska) jezika u obrazovne sisteme zemalja članica Evropske Unije. Pored toga, od 2000. godine Evropska Komisija preporučuje uvođenje CLIL metode u srednjim školama, kao i interdisciplinarnog pristupa u nastavi (Juridisi 2006: 8-9).

U skladu sa predmetom našeg rada opisaćemo trenutnu orgnanizaciju CLIL nastave u obrazovnom sistemu Srbije izdojivši izazove pred kojima se nalaze učenici i nastavnici, te na osnovu prakse evropskih zemalja predložiti dalje smernice u cilju poboljšanja kvaliteta ovog oblika nastave.

\section{Dvojezična (CLIL) nastava u obrazovnom sistemu Srbije od 2000. godine}

Ministarstvo obrazovanja Republike Srbije pokrenulo je 2000. godine niz projekata u cilju osavremenjivanja obrazovnog sistema u zemlji. S tim u vezi, predviđeno je uvođenje najmanje dva strana jezika tokom osnovnog i srednjoškolskog obrazovanja, kao i tri ili više stranih jezika koji bi imali status izbornih predmeta. Takođe, pomenuta reforma podrazumevala je i mogućnost uvođenja CLIL (dvojezične) nastave koja bi podrazumevala dualnu upotrebu stranog i maternjeg jezika na osnovnoškolskom i srednjoškolskom nivou (Filipović i dr. 2007: 234).

Model CLIL nastave uvodi se od školske 2004/2005. u Trećoj beogradskoj gimnaziji na francuskom, odnosno italijanskom jeziku rešenjem Ministarstva prosvete i sporta Republike Srbije kojim je ovaj oblik nastave definisam kao ogledni (Vučo 2006:42). Nakon toga, širom zemlje obrazuju se dvojezična odeljenja, kako u srednjim, tako i u osnovnim školama, koja podrazumevaju upotrebu različitih stranih jezika kao posrednih u nastavi. Trenutno CLIL (dvo- 
DVOJEZIČNA (CLIL) NASTAVA U OBRAZOVNOM SISTEMU SRBIJE ...

jezična) nastava zastupljena je u 14 osnovnih i 16 srednjih škola u kojima se nastava izvodi na engleskom, nemačkom, ruskom, francuskom ili italijanskom jeziku i srpskom, odnosno jeziku nacionalne manjine. ${ }^{1}$ Godine 2015. ministar prosvete donosi „Pravilnik o bližim uslovima za ostvarivanje dvojezične nastave “2 (u daljem tekstu PDN) kojim se detaljnije određuju pojedini aspekti ovakvog oblika nastave. Naime, u PDN-u su prisutni sledeće aspekti nastave: uslovi koje škole treba da ispune u cilju dobijanja saglasnosti za izvođenje dvojezične nastave, mogućnosti uvođenje dvojezične nastave na osnovnoškolskom, odnosno srednjoškolskom niovu, neophodni jezički nivo za upis u ova odeljenja, traženi jezički nivo nastavnika koji su uključeni u dvojezičnu nastavu, kao i način praćenja i vrednovanja kvaliteta izvođenja dvojezične nastave.

Međutim, PDN ne određuje detaljnije sledeće elemente koje smatramo značajnim za uspešno izvođenje CLIL nastave: status i usavršavanje nastavnika, upotrebu udžbenika i drugih didatkičkih materijala, kriterijume za ocenjivanje učenika, kao i završni (maturski) ispit. U narednim poglavljima prikazaćemo iskustva drugih zemalja u vezi sa pomenutim aspektima nastave koja mogu poslužiti kao modeli poboljšanje kvaliteta dvojezične nastave u okviru obrazovnog sistema Srbije.

\section{Usavršavanje CLIL nastavnika: iskustva iz inostranstva}

S obzirom da CLIL nastava podrazumeva, sa jedne strane, nastavu na stranom i maternjem jeziku i podučavanje nastavnog (nejezičkog) predmeta i stranog jezika sa druge strane, proizilazi potreba da CLIL nastavnik bude obučen da podučava svoj predmet kroz strani jezik, tačnije, da omogući učeniku istovremeno usvajanje nejezičkog sadržaja i stranog jezika. Slično ovome, nastavnik stranog jezika osmišljava nastavu kroz upotrebu stranog jezika na tekstovima različite tematske sadržine u cilju razvijanja akademske kompetencije (Dejl i Taner 2012).

1 Prema podacima koordinatorke za dvojezičnu nastavu Tatjane Jovanović pri Ministarstvu prosvete, nauke i tehnološkog razvoja Republike Srbije.

2 Službeni glasnik RS“, br. 105/2015, 50/2016. 
Na osnovu pomenutih karakteristika CLIL nastave jasno je da je poznavanje stranog jezika za nastavnika od izuzetne važnosti, ali nije isključivo i jedini uslov za kvalitetnu nastavu. U većini evropskih zemalja usavršavanje nastavnika podrazumeva pohađanje CLIL kurseva (u vezi sa metodama i tehnikama rada), kao i kurseva za usavršavanje određenog stranog jezika, najčešće pri Univerzitetima $^{3}$. Naime, kursevi uglavnom podrazumevaju uvođenje nastavnika u opšte teorijske osnove didaktičko-metodoloških aspekata CLIL nastave, kao i upoznavanje nastavnika sa specifičnim didaktičkim odlikama određenih nejezičkih predmeta koji se izvode na datom posredničkom jeziku. Pored toga, kao što je slučaj u Italiji, kursevi obično podrazumevaju i praktični deo u vezi sa CLIL metodologijom za prirodne i društvene nauke koje se izvode na posrednim jezicima kao što su engleski, francuski, nemački ili španski jezik. Pored mogućnosti usavršavanja nastavnika pri lokalnim unverzitetskim centrima ili takozvanim agencijama za usavršavanje nastavnika, nastavnici često imaju podršku lokalnih institucija da pohađaju pomenute specijalizovane kurseve i u inostranstvu (kao što je slučaj sa Španijom). Takođe, najčešća praksa pri pomenutim centrima za usavršavanje podrazumeva i umrežavanje nastavnika u cilju razmene iskustava i didaktičkih materijala. Pored Univerziteta, pojedine zemlje (poput Španije) omogućavaju nastavnicima obuke pri centrima za usavršavanje nastavnika koje se mogu pratiti direktno ili preko on-line kurseva. Podrška nastavnicima u praksi ogleda se i u mogućnosti da se obezbedi tzv. asistent za strani jezik uz pomoć Evropske komisije za permanentno obrazovanje koji sarađuje kako sa nastavnikom nejezičkog predmeta, tako i sa nastavnikom stranog jezika.

\section{Usavršavanje CLIL nastavnika u Srbiji}

Obrazovni sistem Republike Srbije propisuje kontinuirano usavršavanje nastavnika kako na osnovnoškolskom, tako i na srednjoškolskom nivou. Pri relevantnim državnim centrima i institucijama

3 Detaljnije o kursevima za usavršavanje CLIL nastavnika: Zavišin 2017a. 
DVOJEZIČNA (CLIL) NASTAVA U OBRAZOVNOM SISTEMU SRBIJE ...

koje se bave organizacijom seminara i kurseva za usavršavanje nastavnika ${ }^{4}$ nastavnici imaju mogućnost da razvijaju nastavničke kompetencije koje su grupisane u četiri glavne oblasti: nastavna oblast, predmet i metodika nastave (K1), poučavanje i učenje (K2), podrška razvoju ličnosti učenika (K3) i komunikacija i saradnje (K4). Tako, na osnovu profesionalnih prioriteta svaki nastavnik može da izabere seminare i obuke u toku školske godine koje će pohađati. S tim u vezi, nastavnici su do sada imali mogućnost da pohađaju nekoliko seminara i u vezi sa temama koje se tiču CLIL nastave ${ }^{5}$.

Pored navedenih kurseva za usavršavanje koji su dostupni svim nastavnicima, najčešće postoji i mogućnost usavršavanja nastavnika koju pruža država čiji jezik je posredni jezik u CLIL nastavi. Reč je najčešće o međudržavnoj saradnji između Republike Srbije i date zemlje koja se obavezuje na različite oblike podrške bilingvalnoj nastavi, a jedan od aspekata saradnje podrazumeva i obezbeđivanje stipendija za pohađanje kurseva za usavršavanje stranog jezika nastavnicima koji su uključeni u CLIL nastavu. ${ }^{6}$

\section{Udžbenici i didaktički materijali u CLIL-u}

S obzirom da je u okviru obrazovnog sistema Srbije izostavljena preporuka nastavnicima u CLIL kontekstu u vezi sa odabirom udžbenika i didaktičkog materijala, smatramo da je od izuzetne važnosti skrenuti pažnju na ovaj izazov sa kojima se susreću nastavnici na samom početku uključivanja u ovaj oblik nastave.

Naime, na osnovu prakse evropskih i drugih zemalja u vezi sa upotrebom posebnih didaktičkih materijala za kontekst CLIL nastave, napomenuli bismo da prevođenje knjiga sa maternjeg jezika na

$4 \quad$ Centar za profesionalni razvoj zaposlenih u obrazovanju pri Zavodu za unapređivanje obrazovanja i vaspitanja (skr. ZUOV), dostupan na http:// www.zuov.rs/ i Zavod za vrednovanje kvaliteta obrazovanja i vaspitanja (skr. ZVKV), dostupan na: http://ceo.edu.rs/

5 http://zuov-katalog.rs/index.php?action=page/catalog

6 Jedan od takvih primera je Memorandum o saradnji između Republike Italije i Republike Srbije: http://www.ambbelgrado.esteri.it/ambasciata belgrado/sr/i_rapporti_bilaterali/cooperazione\%20culturale 
strani nije pružilo zadovoljavajuće rezultate. Stoga, najčešća praksa u ovoj oblasti podrazumeva samostalnu pripremu materijala za CLIL nastavu. S tim u vezi, nastavnici koriste u nastavi različita pomoćna sredstva savremene tehnologije (video i audio pomagala, Internet i sl.), kao i različite dodatne tekstualne materijale (Juridis 2006).

Takođe, istakli bismo praksu tzv. Evropskih škola u kojima nastavnici, pored samostalne pripreme i prilagođavanja didaktičkih materijala u skladu sa potrebama nastave i jezičkim nivoom učenika, sastavljaju i višejezične rečnike stručnih termina. Ovakvi rečnici pružaju nastavniku dodatnu sigurnost da su učenici usvojili određenu terminologiju, kako na stranom, tako i na maternjem jeziku ( Birdsmor 1993: 121 - 155).

\section{Kriterijumi za ocenjivanje u CLIL nastavi}

S obzirom da tema našeg rada nije detaljna (glotodidaktička) analiza pojedinih aspekata CLIL nastave nećemo se detaljnije baviti problemom ocenjivanja, već ćemo u kratkim crtama ilustrovati složenost ovog izazova kako bismo ukazali na potrebu za pružanje podrške nastavnicama u rešavanju datog problema. Naime, u vezi sa ocenjivanjem učenika u CLIL nastavi među nastavnicima je prisutna nedoumica šta ocenjivati u produkciji učenika (jezik i/ili sadržaj) i koje kriterijume primenjivati.

Prema opštim preporukama (Juridis 2006: 29) nastavnik treba prevashodno da ocenjuje sadržaj nejezičkog predmeta, ali se istovremeno preporučuje međusobna saradnja nastavnika nejezičkog predmeta i nastavnika stranoge jezika u definisanju kriterijuma za ocenjivanje.

Koliko je složeno pitanje ocenjivanje učenika u CLIL nastavi moguće je videti na osnovu analize elemenata sadržaja i jezika na koju ukazuju pojedini autori (Kojl i dr. 2010: 116-119). Tako, prilikom ocenjivanja najezičkog sadržaja nastavnik treba da ima u vidu sledeće elemente: podatke tj. činjenice koje učenik navodi u vezi sa datim predmetom, stepen opšteg razumevanja materije, veštinu manipulacije sadržajem (koristeći se veštinama višeg kognitivnog nivoa kao što su tumačenje, analiza, sinteza i primena sadržaja), kao i stepen veštine 
DVOJEZIČNA (CLIL) NASTAVA U OBRAZOVNOM SISTEMU SRBIJE ...

koju učenik poseduje u samostalnom istraživanju. Sa druge strane, prilikom ocenjivanja jezika nastavnik treba da ima na umu da jezik podrazumeva sledeće aspekte koje učenik treba da usvoji: poznavanje specifične terminologije predmeta, sposobnost upotrebe odgovarajućih jezičkih (morfo-sintaksičkih) struktura u cilju izražavanje slaganja/ neslaganja sa sagovornikom, sopstvenog mišljenja, kao i sposobnost postavljanja pitanja i prenošenja različitih rezultata, izveštaja i slično, potom, stepen usmenog i pismenog razumevanja sadržaja, kao i nivo posedovanja svesti o gramatičkim odlikama jezika.

Ocenjivanje u CLIL nastavi predstavlja jedan od većih izazova sa kojima se suočava nastavnik, te predstavlja jednu od obaveznih tema koje se obrađuju na pomenutim kursevima usavršavanja nastavnika u svetu, dok obrazovni sistem u Srbiji ne pruža podršku nastavnicima u vezi sa ovom problematikom.

\section{Završni (maturski) ispit u CLIL nastavi: pojedina evropska iskustva}

U ovom poglavlju osvrnućemo se na pojedine primere sadržaja i organizacije maturskog ispita koje bi mogle poslužiti kao smernice za CLIL nastavu u okviru obrazovnog sistema Republike Srbije.

Evropske škole (engl. European schools) najčešće predstavljaju dobre primere CLIL nastave, te ih mnogi autori, poput Bejkera, (Bejker 2007:132) svrstavaju u modele na osnovu kojih je neophodno organizovati nastavnu praksu. Tako na primer, kada je reč o stranim jezicima koji su posredni jezici u nastavi, najčešće je moguće da učenik prati nastavu na najmanje dva strana jezika, dok po-

stoji mogućnost i da se uči i dodatni, četvrti strani jezik. Kada je reč o maturskom (završnom) ispitu, učenicima se pruža mogućnost da izaberu predmete koje će polagati na maternjem i stranom jeziku, dok se drugi strani jezik polaže kao zaseban predmet ili kao posredni jezik u CLIL kontekstu (Birdsmor, 1993: 121,122).

Interesantna je praksa u francuskim dvojezičnim školama (Tardju i Dolitski 2012: 4) u kojima je polaganje maturskog ispita na stranom jeziku uslovljeno prethodnim polaganjem ispita stranog jezika na nivou B2 prema Zajedničkom evropskom referentnom okviru. 
Italijanski obrazovni sistem omogućava učenicima da izaberu predmet koji su pratili na stranom jeziku kao jedan od maturskih ispita. Naime, učenici mogu da polažu pismeni deo nejezičkog predmeta čija se nastava odvijala u skladu sa CLIL metodom na maternjem jeziku, dok usmeni deo ispita podrazumeva polaganje na stranom jeziku ukoliko je nastavnik koji je izvodio nastavu na stranom jeziku jedan od članova ispitne komisije ${ }^{7}$.

Kada je reč o Mađarskoj, napomenuli bismo cilj koji se postavlja pred učenike u CLIL programima, a koji podrazumeva da učenici koji prate dvojezičnu nastavu steknu jednake kompetencije iz nejezičkih predmeta, odnosno kao i učenici koji prate nastavu na maternjem jeziku. Takođe, mađarski školski program podrazumeva izuzetno visok nedeljni fond časova stranog jezika, posebno tokom prve godine gimnazije ( 12 časova nedeljno). Za završni ispit učenici mogu, ukoliko žele, da polažu nejezički predmet na stranom jeziku. ${ }^{8}$

Zajedničko za sve evropske zemlje koje neguju CLIL nastavu na srednjoškolskom nivou jeste da izdaju učenicima potvrdu da su pratili nastavu u ovom dvojezičnom kontekstu. Uglavnom bilateralni sporazum osigurava učenicima prohodnost ka fakultetima, te stoga učenici iz Češke, Poljske, Nemačke, Mađarske i Bugarske ne polažu prijemni test za upis na fakultete u datim zemljama (Juridis 2006: 29).

\section{Završni (maturski) ispit u CLIL kontekstu u obrazovnom sistemu Srbije}

Organizacija i sadržaj završnog maturskog ispita za učenike koji su pratili nastavu u skladu sa CLIL metodom nisu obuhvaćeni do sada ni jednim pravilnikom u obrazovnom sistemu Srbije, te se za ovaj ispit primenjuje zakon za gimnazije društveno-jezičkog

7 Detaljnije informacije dostupne na sajtu http://www.miur.gov.it/web/ guest/domande-e-risposte

8 U radu je opisan primer mađarsko-engleske gimnazije Tončiš Mihalj (mađ. Táncsics Mihály) koja primenjuje CLIL nastavu u svom kurikulum, detaljnije na sajtu: http://archive.ecml.at/mtp2/ensemble/results/Kapitanffy.htm 
DVOJEZIČNA (CLIL) NASTAVA U OBRAZOVNOM SISTEMU SRBIJE ...

smera (Zakon o srednjem obrazovanju Republike Srbije) ${ }^{9}$. U skladu sa pomenutim propisima maturski ispit se sastoji iz dva dela: zajedničkog i izbornog. U okviru zajedničkog dela završnog ispita učenici polažu pismeno srpski jezik i književnost i jedan od sledećih predmeta: strani jezik ili matematiku. Ispit iz stranog jezika podrazumeva isključivo pismeni prevod nepoznatog teksta na stranom jeziku pri čemu se učenici mogu služiti dvojezičnim i jednojezičnim rečnicima.

Pored toga, za izradu završnog (maturskog) rada učenici imaju mogućnost da izaberu bilo koji nastavni predmet, uključujući i predmet koji su pratili na maternjem jeziku. U slučaju izbora predmeta koji nije bio deo dvojezične nastave, maturski rad podrazumeva upotrebu isključivo maternjeg jezika. Sa druge strane, ukoliko se učenik opredeli za predmet koji je pratio na stranom jeziku, u obavezi je da završni rad izradi na maternjem i stranom jeziku. Rad se brani usmeno na stranom jeziku, uz moguću upotrebu i maternjeg jezik ${ }^{10}$.

\section{Smernice za dalji razvoj dvojezične nastave}

U skladu sa predmetom naše analize CLIL nastave u obrazovnom sistemu Srbije koja je obuhvatila prevashodno sledeće elemente dvojezične nastave: usavršavanje nastavnika, upotreba udžbenika i didaktičkog materijala, kriterijumi za ocenjivanje i sadržaja završnog (maturskog) rada, možemo zaključiti da su pomenuti aspekti nedovoljno ili ni malo zastupljeni u važećim pravilnicima.

$\mathrm{Na}$ osnovu poređenja organizacije CLIL nastave u pojedinim evropskim zemljama i u Republici Srbiji moguće je izdvojiti nekoliko glavnih smernica koje bismo preporučili kao neophodne promene u sadašnjoj praksi dvojezične nastave.

U vezi sa usavršavanjem nastavnika u dvojezičnom kontekstu neophodno je predvideti CLIL kurseve pri univerzitetskim centrima (na primer, na Filološkom fakultetu Univerziteta u Beogradu). Tako,

9 http://www.smsso.edu.rs/assets/zakon-o-srednjem-obrazovanju-ivaspitanju.pdf

10 Opisani model predstavlja praksu u Trećoj beogradskoj gimnaziji, italijanskosrpske sekcije. Detaljnije u: Zavišin 2017b: 74-77 
u skladu sa evropskim modelima obuke CLIL nastavnika istakli bismo neophodnost za organizovanjem dva tipa kursa: prvog, koji bi podrazumevao usavršavanje stranog jezika koji je posredni jezik u nastavi i drugog, koji bi obuhvatio obuku nastavnika iz metodike CLIL nastave, kako za nastavnike stranih jezika, tako i za nastavnike nejezičkih predmeta (up. Zavišin 2017a: 176-179).

Kada je reč o upotrebi udžbenika i didaktičkog materijala neophodno je omogućiti nastavnicima pristup i nabavku stručne literature iz inostranstva, kao i razmenu iskustava i materijala kako u Republici Srbiji, tako i u inostranstvu. Ova razmena bi mogla da se organizuje preko mreža institucija koje su zadužene za usavršavanje i obuku nastavnika. S tim u vezi, smatramo da bi bilo korisno da nastavnici naprave sopstvene baze podataka didaktičkih materijala i dvojezičnih i jednojezičnih rečnika koje bi mogli da razmenjuju preko pomenute mreže.

U vezi sa izazovom koji se odnosi na definisanje kriterijuma za ocenivanje u CLIL nastavi smatramo da bi bilo neophodno, na nivou obrazovnih insititucija, oformiti stručni tim koji bi se sastojao od CLIL stručnjaka, nastavnika stranog jezika i nastavnika nejezičkih predmeta koji bi izdvojili kriterijume kao preporuke za ocenjivanje učenika u datom kontekstu.

$\mathrm{Na}$ osnovu poređenja evropskih iskustava za maturski ispit, smatramo da je neophodno posebno definisati strukturu završnog ispita za dvojezična odeljenja. Naime, kada je reč o stranom jeziku ${ }^{11}$, smatramo da bi struktura ovog ispita trebalo da bude koncipirana po ugledu na strukturu međunarodnih testova na nivou B2 Zajedničkog evrospkog referentnog okvira (prema važećem programu za gimnazije Ministarstva prosvete, nauke i tehnološkog razvoja Republike Srbije jezički nivo koji poseduju učenici za prvi strani jezik na kraju srednjoškolskog ciklusa odgovara nivou B1+ na produktivnom nivou, odnosno B2 na receptivnom nivou ${ }^{12}$ ). Sa druge strane, za maturski ispit koji se odnosi na nejezički predmet čija se nastava izvodila u dvojezičnom kontestu, smatramo da je opisana evropska praksa dragocena kao smernica za definisanje strukture maturskog ispita i u našoj sredini. S tim u vezi, preporučili bismo da pismeni

11 Detaljnije o predloženoj strukturi završnog ispita videti u: Zavišin 2017b.

12 Prosvetni glasnik,Službeni glasnik RS, br. 7, od 27.11.2011. (str. 31-53) 
DVOJEZIČNA (CLIL) NASTAVA U OBRAZOVNOM SISTEMU SRBIJE ...

rad datog predmeta bude na maternjem jeziku, dok bi usmeni deo ispita bio na stranom jeziku uz prisustvo nastavnika stranog jezika i nejezičkog predmeta ${ }^{13}$.

Smatramo da su izneti predlozi za izmene navedenih elemenata CLIL nastave neophodni za dalji razvoj ovog oblika nastave, kao i za poboljšanje postojećeg kvaliteta dvojezične nastave u Republici Srbije.

\section{IZVORI}

Centar za profesionalni razvoj zaposlenih u obrazovanju. Zavod za unapređivanje obrazovanja i vaspitanja.

[http://www.zuov.rs/], (pristupljeno 4.12.2018.)

Evropske škole. [https://www.eursc.eu/en/European-Schools/mission], (pristupljeno 02.12.2018.)

Juridisi 2006: Eurydice. Content and Language Integrated Learning (CLIL) at School in Europe. Brussels: European Commission.

Katalog za usavršavanje nastavnika. Zavod za unapređivanje obrazovanja i vaspitanja.

[http://zuov-katalog.rs/index.php?action=page/catalog], (pristupljeno 3.12.2018.)

Mađarsko-engleska gimnazija Tončiš Mihalj (mađ. Táncsics Mihály): [http://archive.ecml.at/mtp2/ensemble/results/Kapitanffy.htm], (pristupljeno 30.11.2018.)

Maturski ispit za srednje škole u Republici Italiji. [http://www.istruzione.it/esame_di_stato/index.shtml] [https:// www.studenti.it/seconda_prova_liceo_linguistico_esame_di_ maturita.html], (pristupljeno 30.11.2018.)

Memorandum o saradnji između Republike Italije i Republike Srbije. [http://www.ambbelgrado.esteri.it/ambasciata_belgrado/sr/i_rapporti_ bilaterali/cooperazione\%20culturale], (pristupljeno 2.12.2018.)

Ministarstvo prosvete Republike Italije (CLIL obrazovanje). [http://www. miur.gov.it/clil], (pristupljeno 30.11.2018.)

Pravilnik o bližim uslovima za ostvarivanje dvojezične nastave: Službeni glasnik RS, br. 105/2015, 50/2016.

[https://www.paragraf.rs/izmene_i_dopune/120417-pravilnik_o_ dopunama_pravilnika_o_blizim_uslovima_za_ostvarivanje_ dvojezicne_nastave.html], (pristupljeno 3.13.2018.)

13 Detaljnije o strukturi završnog ispita videti u: Zavišin 2017b. 
Zakon o srednjem obrazovanju Republike Srbije. [http://www.smsso. edu.rs/assets/zakon-o-srednjem-obrazovanju-i-vaspitanju.pdf], (pristupljeno 3.12.2018.)

Zavod za vrednovanje kvaliteta obrazovanja i vaspitanja. [http://ceo.edu. rs/], (pristupljeno 4.12.2018.)

\section{LITERATURA}

Bejker 2007: Baker, C. Becoming bilingual through bilingual education. u: Auer, P./Wei, L. (ur.), Handbook of Multilingualism and Multilingual Communication, Berlin: Walter de Gruyter.

Birdsmor 1993: Beardsmore, H. B. The European School Model, u: Beardsmore, H. B. (ur.),

European Models of Bilingual Education, Clevedon: Multilingual Matters LTD, $121-155$.

Kojl, Hud i Marš 2010: Coyle, D./Hood,S P./Marsh, D. CLIL. Content and Language Integrated Learning. Cambridge: Cambridge University Press.

Dejl i Taner 2012: Dale, L./Tanner, R. CLIL Activities. A resource for subject and language teachers. Cambridge: Cambridge University Press.

Filipović, Vučo i Đurić 2007: Filipović J./Vučo, J./Đurić, Lj. Critical Review of Language Education Policies in Compulsory Primary and Secondary Education in Serbia, u: Current Issues in Language Planning, Channel View Publication, VIII (1), 222-242.

Marš 2002: Marsh, D. CLIL/EMILE - The European Dimension. Jyväskylä: University of Jyväskylä.

Tardju i Dolitski 2012: Tardieu, C./ Dolitsky, M. Impact of the CEFR on CLIL Integrating the

Task-Based Approach to CLIL teaching, u: Agudo J. d. D. M. (ur.), Teaching and Learning English through Bilingual Education, Cambridge: Cambridge Scholars Publishing.

Vučo 2006: Vučo, J. U potrazi za sopstvenim modelom dvojezične nastave. u: Inovacije u nastavi, Beograd: Učiteljski fakultet, XIX, 41-54.

Vučo 2014: Вучо, J. Двојезична настава страних језика у Србији, у: Филиповић, J./

Дурбаба, О. Страни језици у образовном систему и језичке образовне политике. Београд: Филолошки факултет, 99-146.

Zavišin 2017a: Zavišin, K. Nastava jezičkih i nejezičkih sadržaja na stranom jeziku - predlog modela kursa za usavršavanje nastavnika u CLIL kontekstu, u: Polovina, V. (ur.), Anali Filološkog fakulteta, Beograd: Filološki fakultet u Beogradu, 165-181. 
DVOJEZIČNA (CLIL) NASTAVA U OBRAZOVNOM SISTEMU SRBIJE ...

Zavišin 2017b: Zavišin, K. Završni ispit za strani jezik na kraju srednjoškolskog obrazovanja u dvojezičnoj (CLIL) nastavi: Predlog modela za obrazovni sistem Republike Srbije, u: Polovina, V. (ur.), Anali Filološkog fakulteta, Beograd: Filološki fakultet u Beogradu, 67-82.

\section{Katarina Zavišin}

\section{INSEGNAMENTO BILINGUE (CLIL) NEL SISTEMA EDUCATIVO SERBO: LE SFIDE ATTUALI E LE INDICAZIONI PER IL FUTURO}

\section{Riassunto}

Nel presente articolo viene illustrata la situazione attuale dell'insegnamento bilingue relativo all'approccio CLIL in Serbia. Si noti che il concetto bilingue si riferisce all'uso di una lingua straniera e della L1 degli apprendenti nell'insegnamento delle materie non linguistiche del curriculum scolastico.

Il Ministero della Pubblica Istruzione serbo dal 2000 ha introdotto nel sistema educativo del Paese notevoli innovazioni, tra le quali la possibilità dell'insegnamento bilingue - CLIL nelle scuole medie e superiori. Nell'articolo viene esaminato l'attuale Regolamento sulla realizzazione (attuazione) dell'insegnamento bilingue, ponendo l'accento sugli aspetti mancanti nel documento quali: le condizioni e l'organizzazione dell'aggiornamento continuo degli insegnanti CLIL, l'uso dei manuali e dei materiali didattici supplementari, i criteri per la valutazione degli apprendenti nonchè la struttura dell'esame finale per le scuole superiori (l'esame di maturità). In base all'analisi delle esperienze straniere (innanzitutto di quelle europee) nell'insegnamento CLIL relative alle componenti mancanti nell'organizzazione locale, vengono individuati dei modelli che si potrebbero applicare al sistema attuale del modello CLIL in Serbia. Tali modelli, adattati al sistema educativo locale, vengono proposti come indicazioni per un ulteriore sviluppo del modello CLIL in Serbia.

Parole chiave: CLIL, insegnamento bilingue, aggiornamento insegnanti, materiali didattici, valutazione, esame di maturità 